\title{
OSTEOCHONDROMA OF THE INFERIO-MEDIAL BORDER OF SCAPULA: A RARE SITE FOR OSTEOCHONDROMA
}

Gagan Khanna' ${ }^{1}$, Rajan Sarad ${ }^{2}$

\section{HOW TO CITE THIS ARTICLE:}

Gagan Khanna, Rajan Sarad. "Osteochondroma of the infero-medial border of scapula: a rare site for osteochondroma". Journal of Evolution of Medical and Dental Sciences 2013; Vol. 2, Issue 41, October 14; Page: 7951-7954.

ABSTRACT: OBJECTIVE: To report a case of scapular osteochondroma extending from infero medial border to dorsal surface associated with pain and winging that is rarely reported in the medical literature. CASE PRESENTATION AND IDENTIFICATION: A19-year-old male presented with pain and winging of the left scapula. CT scan revealed an osteochondroma of the medial border of the scapula with extensive growth over the dorsal surface beneath infraspinatus. Excision of the tumour relieved the symptoms. Pathological study showed osteochondroma of the scapula. In a follow-up 1 year later he was free of pain with no clinical or radiological sign of recurrence. CONCLUSION: A case of scapular osteochondroma associated with pain and winging treated by excision and follow-up showed no sign of clinical or radiological recurrence.

INTRODUCTION: Osteochondroma is the most common benign tumour of the bones (1, 2). Most of which occurs in long bone at its metaphyseal region. Rarely the tumour occurs in flat bones; its incidence in scapula is less than $4 \%$ (3). Most of the osteochondroma of the scapula are asymptomatic but carries an inherent risk of malignant transformation as with the osteochondromas of flat bone, and winging of scapula. Here we report a large osteochondroma arising from the medial border of the right scapula in a young adult male with a large sessile extension over the dorsal surface beneath the infrascapular muscle and associated with pain and winging.

CASE REPORT: A 17 years old male patient presented to us with the swelling dorsal aspect of left scapular region of 1 year duration with history of progressive increase in size. On examination swelling was oval in horizontal plane, lobulated, $8 \times 6 \mathrm{~cm}$, and bony hard consistency, fixed to underlying scapula from the dorso-medial aspect. The movement at the shoulder joint is normal except the winging of left scapula when pushing the upper limb forward against the wall. No bony prominences are found elsewhere in the body. Patient was admitted for surgical excision for the apprehension of malignant transformation of swelling on part of patient and for the cosmetic reasons. Winging of the scapula was not troublesome for the patient.

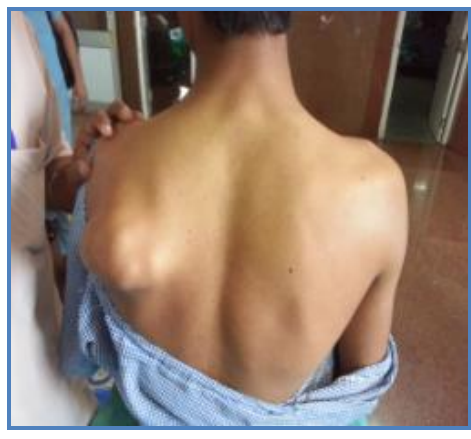

Preoperative photograph of the patient showing the swelling on dorsal aspect of left scapular region 
X-rays examination showed a large sessile bony tumor arising from the dorsal aspect. CT scan showed a mushroom shaped exostosis measuring $8 \times 6 \times 3 \mathrm{~cm}$ from the medulla of the medial aspect of left scapula. Adjoining soft tissue showed normal density. Procedure was performed under general anesthesia and in prone position. The scapular region and the shoulder and arm were cleaned, painted and draped. The shoulder and arm kept free. The approach was dorsally and horizontally oblique starting from inferomedial border to lateral border of scapula centering the swelling. Infraspinatus muscle was split in line with its fibers which were stretched over the swelling. The outer margins of the swelling exposed by staying close the bony swelling, which is arising from the infero-medial border of scapula and sessile growth extending over infraspinatus fossa. The rhomboideus minor and Levator scapulae muscles were detached with a cuff and the mass was subperiosteally exposed on the medial border the short stalk of the tumour.
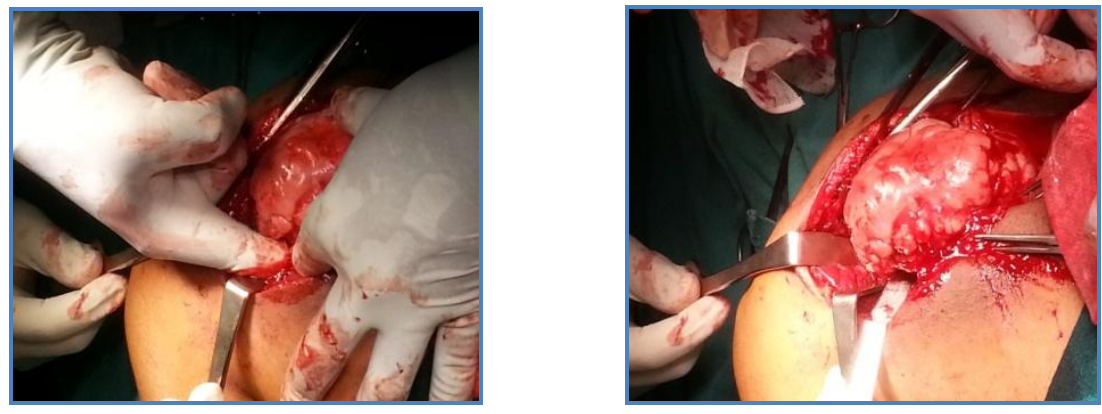

Intraoperative photographs showing the tumour approached by dorsally and horizontally oblique incision starting from inferomedial border to lateral border of scapula centering the swelling

The mass was excised with the help of a small osteotome enmasse. The excised mass measured 8 X 7 X $3 \mathrm{~cm}$. macroscopically it was a pearly white nodular hard mass with the cut surface revealing spongy bone with lobulated cartilaginous cap.

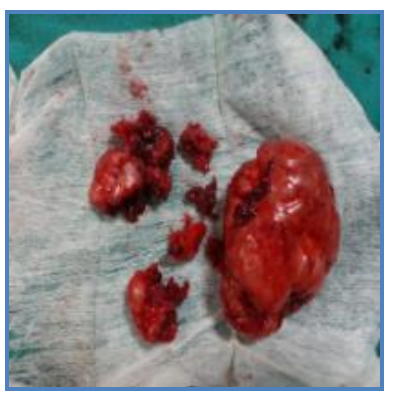

\section{The excised mass measured 8 X 7 X $3 \mathrm{~cm}$.}
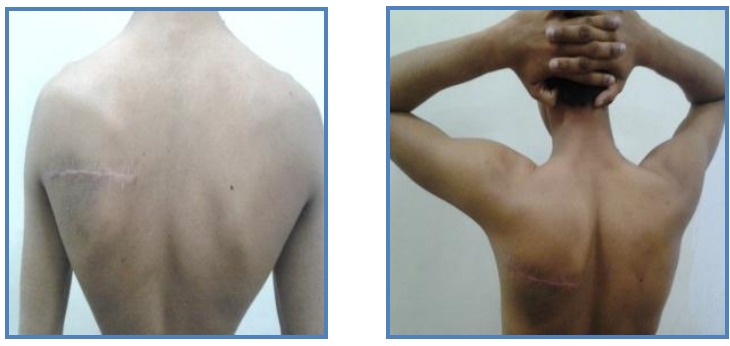

Postoperative photographs of

the patient with healed wound 
DISCUSSION: Osteochondromas are not pure bone tumors, which are usually located in the distal femur, upper tibia or upper humerus. Although the exact aetiology of the growth is not known, a peripheral portion of the physis is thought to herniate from the growth plate. This metaplastic cartilage grows to form the exostosis, which is connected to the bone by a thin stalk [4]. Patients having osteochondroma or exostosis most commonly present in the second decade of life, similar to the present case. A bony mass without pain is the most common presenting symptom. In other cases, diagnosis is made incidentally, based on radiographs. Pain is generally uncommon and is due to pressure on the surrounding soft tissue, underlying bursitis, fracture of the stalk [4].Rarely osteochondroma occurs in flat bone like pelvis (5\%) and scapula (4\%) (3). Malignant transformation is more likely to occur in flat bone osteochondroma with $1 \%$ incidence in solitary and $5 \%$ in multiple osteochondromas. Malignant change is characterized by a sudden increase in the size of the tumour accompanied by pain. Thickness of the cartilaginous cap of osteochondroma is one of the predictors for this transformation. A cap thinner than $1 \mathrm{~cm}$ usually indicates a benign condition, whereas a cap between 1 and $2 \mathrm{~cm}$ may be considered questionable, and a cap thicker than $2 \mathrm{~cm}$ generally corresponds to malignant transformation ${ }^{[8]}$. Treatment of osteochondroma is achieved by resection of the tumour, including its stalk. Incomplete resection can lead to recurrence. In solitary osteochondroma local recurrence after resection is less than $2 \%$.

Plain radiography is the main diagnostic modality. Anteroposterior and lateral radiographs are sufficient to characterize the lesion. In certain bones such as the pelvis and the scapula, a CT scan is useful to localize the lesion when planning resection as was done in this patient. MRI is needed only if malignancy is suspected (5).

Swelling was the most common clinical presentation reported. Winging of the scapula [6, 7], mechanical blockage of free movements at the shoulder joint can occur.

\section{REFERENCES:}

1. Pongkripetch M, Sirikulchayanonta V: Analysis of bone tumors in Ramathibodi Hospital, Thailand, during 1977-1986: study of 652 cases. J Med Assoc Thai 1989; 72: 621- 628.

2. Barbosa CS, Araujo AB, Miranda D: Incidence of primary benign and malignant neoplasms and bone pseudo tumoral lesions: an epidemiologic analysis of 585 cases diagnosed at the Faculdade de Medicina of the Universidade Federal de Minas Gerais. AMB Rev Assoc Med Bras 1991; 37: 187-192.

3. Calafiore G, Calafiore G, Bertone C, Urgelli S, Rivera F, Maniscalco P: Osteochondroma: report of a case with atypical localization and symptomatology. Acta Biomed AteneoParmense 2001; 72: 91-96.

4. Essadki B, Moujtahid M, Lamine A, Fikry T, Essadki O, Zryouil B: Solitary osteochondroma of the limbs: clinical review of 76 cases and pathogenic hypothesis. ActaOrthopBelg 2000; 66: 146-153.

5. Erlemann R: Benign cartilaginous tumors. Radiology 2001; 41: 548-559.

6. Bloch AM, Nevo Y, Ben-Sira L, Harel S, Shahar E: Winging of the scapula in a child with hereditary multiple exostoses. PediatrNeurol 2002; 26: 74-76.

7. Danielson LG, el-Haddad I: Winged scapula due to osteochondroma: report of 3 children. Acta Orthop Scand 1989; 60: 728-729. 
8. Malghem J, Berg BV, Noel H, Maldague B: Benign osteochondroma and exostosis chondrosarcomas: evaluation of cartilage cap thickness by ultrasound. SkelRadiol 1992; 21: $33-37$

\section{AUTHORS:}

1. Gagan Khanna

2. Rajan Sarad

\section{PARTICULARS OF CONTRIBUTORS:}

1. Associate Professor, Department of Orthopaedics, SGRDIHSR, Amritsar, Punjab.

2. Assistant Professor, Department of Orthopaedics, SGRDIHSR, Amritsar, Punjab.

\section{NAME ADDRESS EMAIL ID OF THE CORRESPONDING AUTHOR:}

Dr. Gagan Khanna,

Associate Professor,

Department of Orthopaedics,

Sri Guru Ram Das Institute of Health Sciences and Research,

Amritsar, Punjab.

Email-drgk75@yahoo.com

Date of Submission: 20/08/2013.

Date of Peer Review: 22/08/2013.

Date of Acceptance: 05/10/2013.

Date of Publishing: 10/10/2013 